ECCOMAS

\section{Proceedia}

COMPDYN 2021

$8^{\text {th }}$ ECCOMAS Thematic Conference on Computational Methods in Structural Dynamics and Earthquake Engineering

M. Papadrakakis, M. Fragiadakis (eds.) Streamed from Athens, Greece, 28 - 30 June 2021

\title{
QUANTIFYING SEISMIC RESILIENCE OF SINGLE-COLUMN ROCKING BRIDGES - A COMPARATIVE STUDY
}

\author{
Anastasios I. Giouvanidis ${ }^{1}$, and You Dong ${ }^{2}$ \\ ${ }^{1}$ University of Minho, ISISE, Department of Civil Engineering \\ Guimarães, Portugal \\ e-mail: agiouvanidis@ civil.uminho.pt \\ ${ }^{2}$ Department of Civil and Environmental Engineering, The Hong Kong Polytechnic University \\ Hung Hom, Hong Kong \\ e-mail: you.dong@polyu.edu.hk
}

\begin{abstract}
This study focuses on structural systems which are particularly attractive for bridge design. Specifically, it investigates the seismic performance of single-column bridges, which are either conventionally designed, with the column monolithically connected with the ground (i.e. fixed-base), or designed with the column-footing system able to uplift and exhibit planar rocking motion during an earthquake. Conventionally designed bridges sustain considerable damage at the column ends after severe earthquakes. Seismic damage often determines whether the bridge remains functional after a seismic event. On the contrary, rocking design implies that a structure under seismic loading performs rigid body rotation around pre-defined pivot points. Thus, in principle, it relieves the structure from excessive deformations and damage. However, rocking isolation is not often applied in bridge engineering practice, mainly due to the lack of thorough understanding of its dynamic (seismic) performance and its potential post-earthquake financial benefits. This paper redirects our attention to the main benefits of rocking design over the conventional (fixed-base) design and conducts a comparative study between the two design methodologies in terms of their seismic losses and resilience in the aftermath of severe seismic hazard scenarios. The analysis reveals the mitigated seismic losses and the remarkable resilience that rocking design offers compared to the conventional (fixed-base) design after all the examined seismic hazard scenarios. The above findings reinforce the potential of the rocking design as an alternative seismic design paradigm for future bridge engineering applications and serve as the basis for a more rational and holistic seismic assessment of single-column rocking bridges.
\end{abstract}

Keywords: Rocking, Analytical dynamics, Fragility, Seismic loss, Resilience. 


\section{INTRODUCTION}

Conventional bridge seismic design implies the column remains fixed with its foundation, and subsequently with the ground, offering the necessary strength and ductility to the structure to withstand seismic forces and avoid collapse. After severe earthquakes though, such a design concept leads to sustainable seismic damage and, thus, residual displacements. Seismic damage is an important measure of post-earthquake functionality that often dictates whether a bridge remains operational following a seismic event. On the other hand, rocking design allows the structure to uplift and pivot during an earthquake relieving the structure from stresses and subsequently seismic damage. The seminal work of Housner [1] first revealed the benefits of rocking design over the conventional (fixed-base) design after the Chilean earthquake in 1960, and many studies have followed $[2,3,4,5,6,7,8,9,10,11,12,13,14,15,16,17]$, among others.

The structural configuration of Fig. 1(a), in which the column is monolithically connected with the ground (i.e. fixed-base), is widely used for bridge design. On the contrary, the configuration of Fig. 1(b) is designed in such a way that the column is monolithically connected with the footing (or base) but the column-base system can detach from the (assumed rigid) ground when subjected to a ground motion. Hence, the rocking structural system of Fig. 1(b) is gaining momentum as an alternative bridge design paradigm, since it combines the benefits of rocking isolation with the merits of the accelerated bridge construction method. To illustrate its superior behavior, various studies have compared its seismic performance with the pertinent performance of its fixed-base counterpart [18, 19, 20, 21, 22, 23, 24, 25], and references therein.

This work is motivated by the lack of analytical studies that thoroughly evaluate the postearthquake performance of the rocking system of Fig. 1. Hence, it extends the well-established performance-based earthquake engineering framework to compare the post-earthquake performance of the conventional design method with the rocking design in terms of: (i) the accumulated seismic (repair) losses, and (ii) the resilience in the aftermath of severe seismic hazard scenarios.

\section{ANALYTICAL MODELLING}

Fig. 1 illustrates the examined single-column structural systems. Fig. 1(a) shows the conventional (fixed-base) design, while Fig. 1(b) illustrates the rocking column-base system that is designed for bridges. Assuming rigid ground conditions and no sliding at the rocking interface allow the structure of Fig. 1(b) to uplift and pivot during an earthquake exhibiting planar rocking motion. When the rocking structure of Fig. 1(b) remains in full contact with the ground, from a dynamics perspective, it behaves as a single degree-of-freedom system (i.e. similar to the fixed-base structure of Fig. 1(a)). Thus, its motion is captured by the deformation of the column $u$. After rocking commences, the motion of the rocking structure is captured by both the deformation of the column $u$ and the rocking rotation $\phi$ of the base [26, 27].

Consider the rocking oscillator of Fig. 1(b) with a concentrated mass $m$ at height $h$. The column has a total mass of $m_{c}$ and elastic stiffness of $E I$ uniformly distributed along its length. The rigid base has mass $m_{b}$ and width $2 b$, while its height is considered negligible compared to its width. For simplicity, assume the lumped mass $m$ creates no moment of inertia, while the rigid base creates moment of inertia with respect to its center of mass equal to $I_{m_{b}}=(1 / 3) m_{b} b^{2}$.

The equations of motion of the rocking oscillator of Fig. 1 can be derived using the general 
(a)

fixed-base

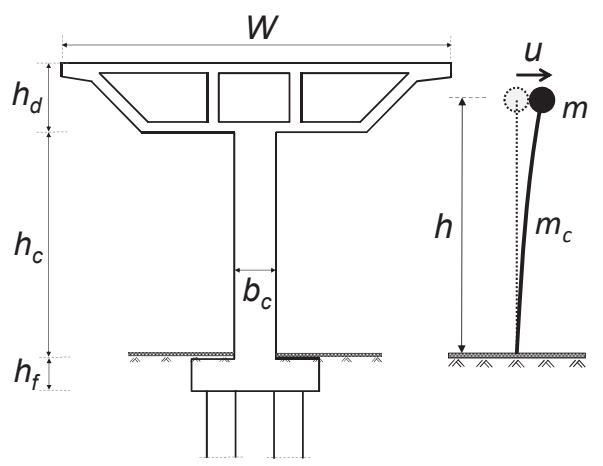

(b)

rocking

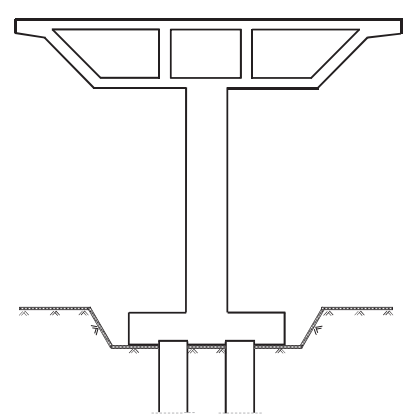

Figure 1: Single-column bridge: (a) designed conventionally with the column monolithically connected with the ground (i.e. fixed-base); and (b) designed with the column-base system able to uplift and pivot during an earthquake

form of the Lagrange's equation:

$$
\frac{d}{d t}\left(\frac{\partial L}{\partial \dot{u}}\right)-\frac{\partial L}{\partial u}=Q, \quad \frac{d}{d t}\left(\frac{\partial L}{\partial \dot{\phi}}\right)-\frac{\partial L}{\partial \phi}=0
$$

where $L=T-V$, with $T$ the kinetic energy, $V$ the potential energy and $Q$ the generalized force, whose mathematical derivations are omitted herein for brevity (see [25] for more details). While the structure of Fig. 1(b) exhibits planar rocking, the equations that describe its motion are [25]:

$$
\begin{aligned}
& \left(m+\frac{33}{140} m_{c}\right) \ddot{u}+\left(m+\frac{11}{40} m_{c}\right) h \ddot{\phi}= \\
& -C \dot{u}-\frac{3 E I}{h^{3}} u+\left[\left(m+\frac{33}{140} m_{c}\right) u-\operatorname{sgn}(\phi)\left(m+\frac{3}{8} m_{c}\right) b\right] \dot{\phi}^{2} \\
& -\ddot{u}_{g}\left(m+\frac{3}{8} m_{c}\right) \cos \phi+g\left(m+\frac{3}{8} m_{c}\right) \sin \phi \\
& \left(m+\frac{11}{40} m_{c}\right) h \ddot{u}+\left[\begin{array}{l}
\left(I_{m_{b}}+m_{b} b^{2}\right)+m\left(h^{2}+b^{2}\right)+m u^{2}-\operatorname{sgn}(\phi) 2 m b u \\
+m_{c}\left(\frac{1}{3} h^{2}+b^{2}\right)+\frac{33}{140} m_{c} u^{2}-\operatorname{sgn}(\phi) \frac{3}{4} m_{c} b u
\end{array}\right] \ddot{\phi}= \\
& -\left(2 m+\frac{33}{70} m_{c}\right) u \dot{u} \dot{\phi}+\operatorname{sgn}(\phi)\left(2 m+\frac{3}{4} m_{c}\right) b \dot{u} \dot{\phi} \\
& +\ddot{u}_{g}\left[\begin{array}{l}
-\operatorname{sgn}(\phi)\left(m+m_{b}+m_{c}\right) b \sin \phi \\
-\left(m+\frac{1}{2} m_{c}\right) h \cos \phi+\left(m+\frac{3}{8} m_{c}\right) u \sin \phi
\end{array}\right] \\
& +g\left[\begin{array}{l}
-\operatorname{sgn}(\phi)\left(m+m_{b}+m_{c}\right) b \cos \phi \\
+\left(m+\frac{1}{2} m_{c}\right) h \sin \phi+\left(m+\frac{3}{8} m_{c}\right) u \cos \phi
\end{array}\right]
\end{aligned}
$$

whereas when it remains in full contact with the ground, the pertinent equation of motion becomes:

$$
\left(m+\frac{33}{140} m_{c}\right) \ddot{u}=-C \dot{u}-\frac{3 E I}{h^{3}} u-\ddot{u}_{g}\left(m+\frac{3}{8} m_{c}\right)
$$

where $C$ is the damping coefficient responsible for the energy dissipation while the structure vibrates. $\ddot{u}$ and $\ddot{\phi}$ denote the flexural and angular acceleration, while $\ddot{u}_{g}$ and $g$ are the ground and gravitational acceleration, respectively.

Rocking initiates when the overturning moment due to the external forces exceeds the restoring moment of the structural system. Therefore, uplift occurs when [25]:

$$
\pm h \frac{m+\frac{11}{40} m_{c}}{m+\frac{33}{140} m_{c}}\left[\begin{array}{l}
C \dot{u}+\frac{3 E I}{h^{3}} u \\
+\ddot{u}_{g}\left(m+\frac{3}{8} m_{c}\right)
\end{array}\right] \mp \ddot{u}_{g}\left(m+\frac{1}{2} m_{c}\right) h-g\left[\begin{array}{l}
\left(m+m_{b}+m_{c}\right) b \\
\mp\left(m+\frac{3}{8} m_{c}\right) u
\end{array}\right]>0
$$


where the upper sign denotes clockwise (positive) rotations and the lower sign counter-clockwise (negative) rotations.

When during rocking, impact occurs, $\phi=0$ and energy is lost. Following [28, 29, 25], this work assumes that after impact the rocking structure remains in full contact with the ground and uplifts when Eq. (5) is satisfied. Under this assumption and through conservation of angular momentum, the post-impact flexural velocity $\dot{u}^{+}$can be expressed as [25]:

$$
\dot{u}^{+}=\dot{u}^{-}+\frac{I_{m_{b}}-m_{b} b^{2}+m_{c}\left(-b^{2}+\frac{1}{3} h^{2}+\frac{33}{140} u^{2}\right)+m\left(-b^{2}+h^{2}+u^{2}\right)}{\left(m+\frac{11}{40} m_{c}\right) h} \dot{\phi}^{-}
$$

where $\dot{u}^{-}$and $\dot{\phi}^{-}$denote the pre-impact flexural and angular velocity, respectively.

\section{RESILIENCE-BASED EARTHQUAKE ENGINEERING ASSESSMENT}

To evaluate the seismic performance of a structural system, the Pacific Earthquake Engineering Research (PEER) Center formulated the performance-based earthquake engineering (PBEE) framework [30, 31]. The PBEE framework encompasses four steps: (i) hazard analysis, (ii) structural analysis, (iii) damage analysis, and (iv) loss analysis. On the other hand, the resilience-based earthquake engineering (RBEE) framework illustrated in Fig. 2 appears to be a more holistic approach and it is considered as an extension of the PBEE in the design process. Specifically, the RBEE additionally incorporates the post-earthquake functionality and resilience of the structure, which are also important indicators to evaluate its seismic performance.

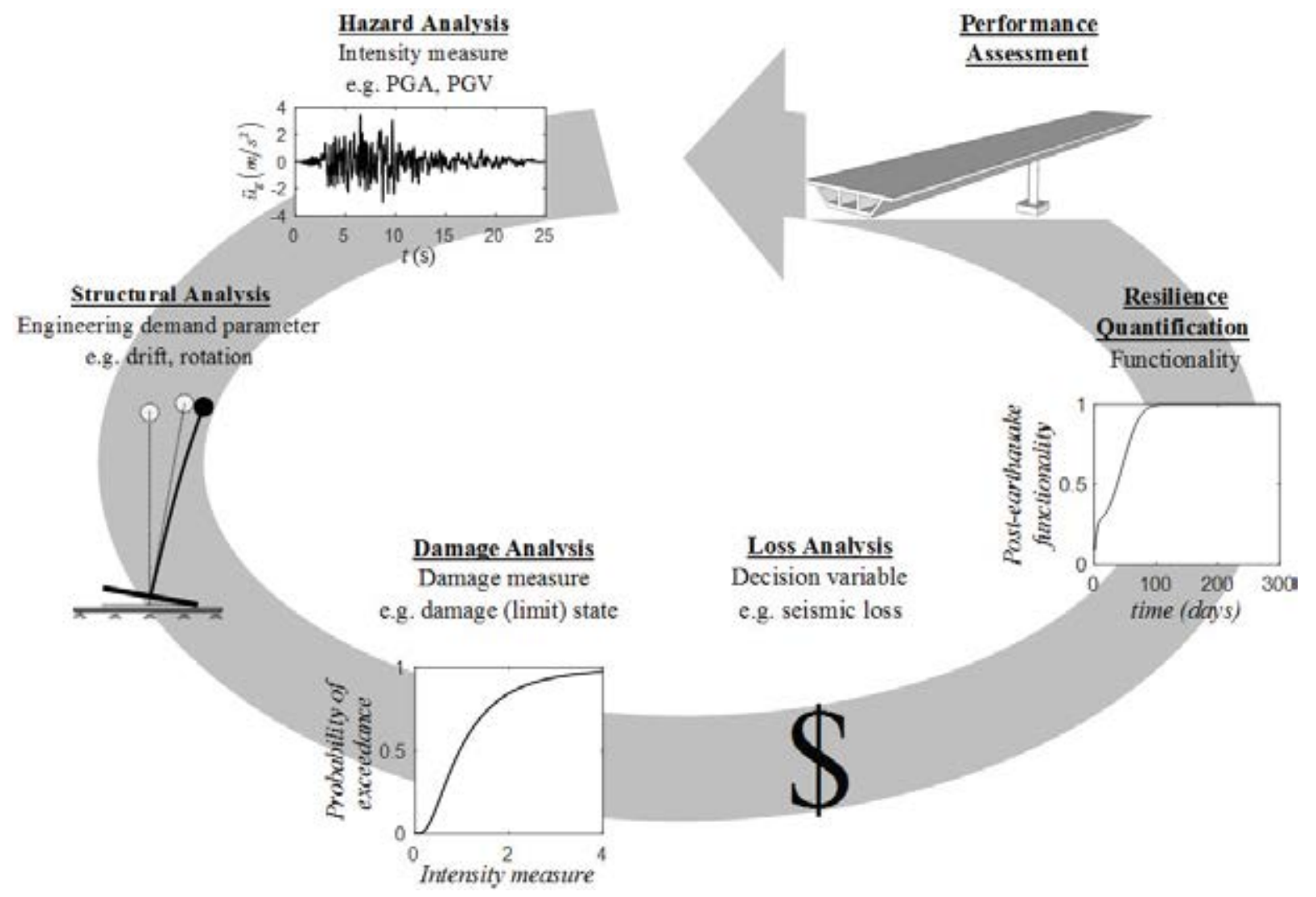

Figure 2: Resilience-based earthquake engineering framework 


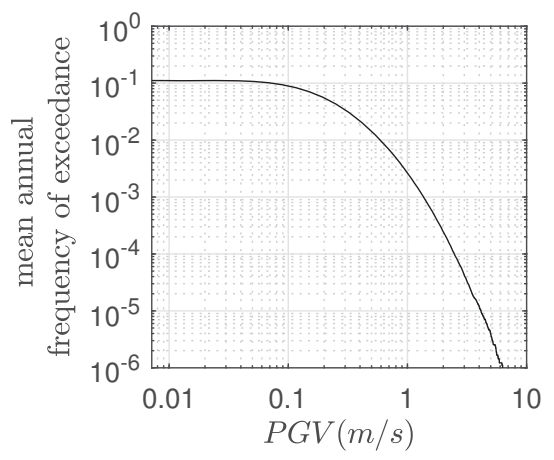

Figure 3: Hazard curve (in logarithmic scale) for the area of focus after conducting probabilistic seismic hazard analysis

\subsection{Hazard Analysis}

Assume that the examined structures of Fig. 1 are located in California laying on a strikeslip fault. The minimum and maximum moment magnitudes $M_{w}$ are taken as 5.5 and 8 , respectively, while the shear wave velocity averaged over the top $30 \mathrm{~m} V_{s, 30}$ is $480 \mathrm{~m} / \mathrm{s}$. The Joyner-Boore distance $R_{J B}$ is $5 \mathrm{~km}$. The IM considered herein is the peak ground velocity $(P G V)[32,33]$. The PSHA provides a sample of 1,000,000 $P G V$ values of ground excitations that are probable to appear in the area of focus [34]. To connect the earthquake events that are likely to appear in the examined area (i.e. California) with their annual frequency of exceedance, the Gutenberg-Richter recurrence law is adopted: $\log _{10} \lambda_{M}=3.94-0.89 M$, where $\lambda_{M}$ is the frequency of the earthquakes with magnitudes greater than $M$. Fig. 3 plots the hazard curve (in logarithmic scale) that provides the mean annual frequency of exceedance $\lambda_{M}$ of every earthquake that is likely to occur in the area of focus characterized by the adopted $P G V$.

\subsection{Structural Analysis}

This section investigates the seismic response of the single-column structural systems of Fig. 1. Each structure is considered to be part of a two-span box-girder bridge of total length $L$ $=60 \mathrm{~m}$ and width $W=10 \mathrm{~m}$. Assume that the total mass of the column is $m_{c}=0.25 \mathrm{~m}$, while the total mass of the base is $m_{b}=0.17 \mathrm{~m}$. The lumped mass $m$ is located at height $h=8 \mathrm{~m}$. The rocking structure of Fig. 1(b) has base-width $2 b=4.6 \mathrm{~m}$ and slenderness $\alpha=0.28 \mathrm{rad}$. In addition, the examined structural systems have identical natural frequency $\omega_{n}=8 p$, where $p=\sqrt{g / R_{m}}$ is the frequency parameter of the rocking oscillator with $R_{m}$ being the diagonal distance of the lumped mass from the pivot point (Fig. 1(b)). The damping ratio $\zeta$ is taken equal to $5 \%$ for the fixed-base oscillator of Fig. 1(a). For the rocking oscillator of Fig. 1(b), this study follows $[27,28]$ and assumes a constant damping ratio of $5 \%$ during rocking and a reduced damping ratio value during full contact (see [27] for further details).

To conduct the structural analysis, appropriate engineering demand parameters (EDPs) need first to be defined. The two EDPs are: (i) the absolute peak flexural deformation $\left|u_{\max }\right|$ normalized with respect to the height $h$, and (ii) the absolute peak rocking rotation $\left|\phi_{\max }\right|$ normalized with respect to the slenderness $\alpha$.

$$
E D P_{1}=\frac{\left|u_{\max }\right|}{h} \quad E D P_{2}=\frac{\left|\phi_{\max }\right|}{\alpha}
$$



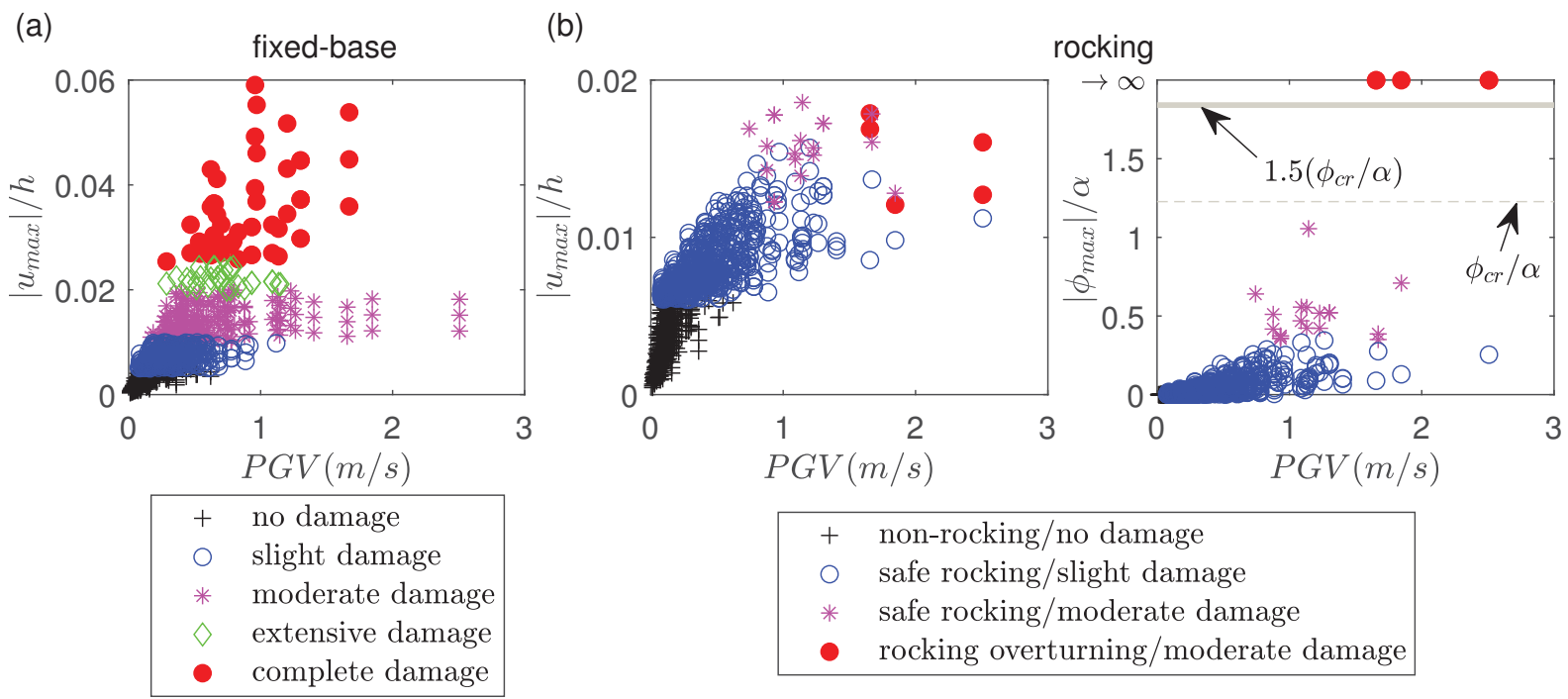

Figure 4: Seismic response analysis of (a) the fixed-base bridge bent of Fig. 1(a), and (b) the rocking bridge bent of Fig. 1(b)

Each of the structural systems of Fig. 1 is subjected to a series of strong ground motions adopted from the Pacific Earthquake Engineering Research (PEER) Center database [35]. The database covers a wide range of both pulse-type and nonpulse-type ground motions with magnitudes $6 \leq M_{w} \leq 8$ and distance from the fault $R_{\text {rup }} \leq 50 \mathrm{~km}$. To induce higher levels of demand, a scale factor of $1,1.25$ and 1.5 is, respectively, assigned to the accelerograms of the adopted database. Therefore, 960 response-history analyses are conducted for each of the examined structural systems of Fig. 1.

Fig. 4 illustrates the seismic response of both structural systems of Fig. 1. As a first approach, Fig. 4 reveals that uplift considerably reduces the structural deformation $\left|u_{\max }\right| / h$ and therefore damage at the column. However, it makes the structure prone to excessive rocking rotations $\left|\phi_{\max }\right| / \alpha$, and thus, overturning. Therefore, Fig. 4 reveals the importance of a proper design for a rocking bridge bent to avoid overturning (or collapse) and at the same time minimize structural damage at the column.

\subsection{Damage Analysis}

The seismic response of a structure is related to the damage occurred at the structure through appropriate damage measures. When excessive damage occurs, the structure collapses (or overturns for the case of a rocking structure) and subsequently it needs to be reconstructed. This work assumes that damage is occurred only at the column of the structure due to seismic forces. To quantify the seismic damage on the fixed-base structure of Fig. 1(a), this section adopts the damage limit states (or limit values of column damage) proposed by [37,36], according to which damage is categorized into four levels/states, i.e. slight, moderate, extensive and complete. Table 1 presents the damage limits states of the fixed-base structure of Fig. 1(a).

On the other hand, the seismic response of the rocking structural system can be adequately described by three damage limit states. This work adopts the damage limits states proposed in [25], which proposed damage limit states for rocking bridge bents based on equivalence of their flexural deformation $\left(\left|u_{\max }\right| / h\right)$ with the pertinent deformation of their fixed-base counterparts. Table 2 presents these damage limits states. In Table 2, $u_{c r}$ is the critical deformation of the column when rocking initiates (i.e. when the condition of Eq. (5) is met), and $\phi_{c r}$ is the critical 


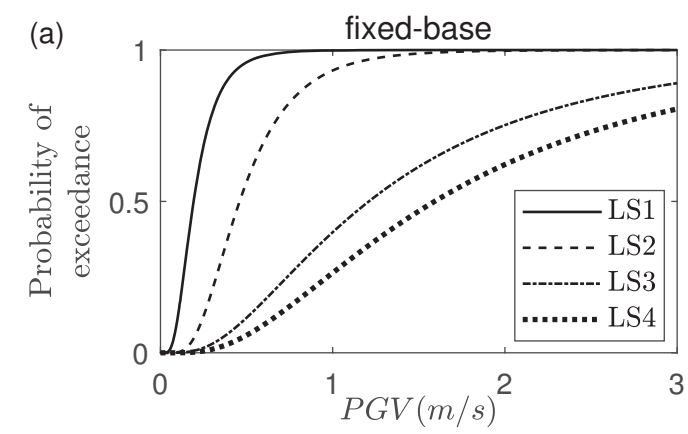

(b)

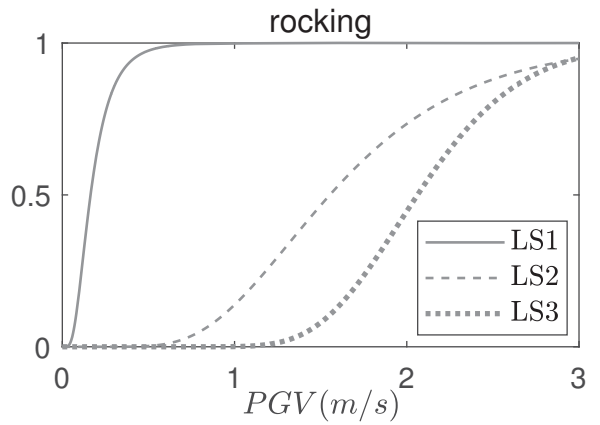

Figure 5: Fragility curves of (a) the fixed-base bridge bent of Fig. 1(a), and (b) the rocking bridge bent of Fig. 1(b) with respect to the adopted intensity measure

rotation for which the structure becomes dynamically unstable [27].

Based on Tables 1, 2, this section employs the the maximum likelihood estimation approach [38] to estimate the probability of the examined structural systems to exceed the certain damage limit states. Fig. 5 plots the fragility curves of the structures of Fig. 1. Note from Fig. 5 and Fig. 4 that, uplift mitigates both structural deformations and the structure's probability to excessive rocking rotations and thus overturning.

\subsection{Loss Analysis}

The structural damage of the examined structures of Fig. 1 accumulated in the aftermath of a seismic event is connected with the seismic losses through decision variables such as: (i) the seismic (repair) losses, (ii) downtime, i.e. the time that is required for the bridge to restore its functionality, and (iii) resilience, i.e. the ability of the bridge to sustain a level of functionality

\begin{tabular}{lll}
\hline $\begin{array}{l}\text { Damage } \\
\text { limit } \\
\text { state }\end{array}$ & $\begin{array}{l}\text { Capacity limit } \\
{[36]}\end{array}$ & Damage description [37] \\
\hline LS1 & $\frac{\left|u_{\max }\right|}{h}=0.005$ & $\begin{array}{l}\text { Slight concrete cracking and spalling at the column. Onset of } \\
\text { yielding of the reinforcing bars. Column in operational condi- } \\
\text { tion (damage requires no more than cosmetic repair) }\end{array}$ \\
\hline LS2 & $\frac{\left|u_{\max }\right|}{h}=0.010$ & $\begin{array}{l}\text { Moderate concrete cracking and spalling at the column. Dam- } \\
\text { age to the exposed reinforcing bars. Minimal residual dis- } \\
\text { placements. Column is still operational (column is structurally } \\
\text { sound, damage is repairable) }\end{array}$ \\
\hline LS3 & $\frac{\left|u_{\max }\right|}{h}=0.020$ & $\begin{array}{l}\text { Extensive flexural damage at the column in the form of buckling } \\
\text { and/or fracture of the longitudinal reinforcing bars, transverse } \\
\text { steel loss, etc. Considerable residual displacements. Column is } \\
\text { not operational (column is structurally unsafe, damage is con- } \\
\text { siderable and repairs are immediate) }\end{array}$ \\
\hline LS4 & $\frac{\left|u_{\max }\right|}{h}=0.025$ & $\begin{array}{l}\text { Complete damage and collapse of the column (column and the } \\
\text { whole bridge need to be reconstructed) }\end{array}$ \\
\hline
\end{tabular}

Table 1: Damage limit states of the fixed-base bridge bent of Fig. 1(a). 


\begin{tabular}{|c|c|c|c|}
\hline $\begin{array}{l}\text { Damage } \\
\text { limit } \\
\text { state }\end{array}$ & Capacity limit [25] & $\begin{array}{l}\text { Response } \\
\text { mode }\end{array}$ & Damage description [37] \\
\hline LS1 & $\frac{\left|u_{\max }\right|}{h}=\frac{u_{c r}}{h}$ & $\begin{array}{l}\text { Rocking ini- } \\
\text { tiation }\end{array}$ & $\begin{array}{l}\text { Slight concrete cracking and spalling at the } \\
\text { column. Onset of yielding of the reinforcing } \\
\text { bars. Column in operational condition (dam- } \\
\text { age requires no more than cosmetic repair) }\end{array}$ \\
\hline LS2 & $\frac{\left|\phi_{\max }\right|}{\alpha}=0.35$ & Safe rocking & $\begin{array}{l}\text { Moderate concrete cracking and spalling at } \\
\text { the column. Damage to the exposed reinforc- } \\
\text { ing bars. Minimal residual displacements. } \\
\text { Column is still operational. Damage at the } \\
\text { pivot points and the abutments due to rocking } \\
\text { motion (column is structurally sound, dam- } \\
\text { age is repairable) }\end{array}$ \\
\hline LS3 & $\frac{\left|\phi_{\max }\right|}{\alpha}=1.5\left(\frac{\phi_{c r}}{\alpha}\right)$ & $\begin{array}{l}\text { Rocking } \\
\text { overturning }\end{array}$ & $\begin{array}{l}\text { Moderate concrete cracking and spalling at } \\
\text { the column. Damage to the exposed reinforc- } \\
\text { ing bars. Minimal residual displacements. } \\
\text { Column is still operational. Damage at the } \\
\text { pivot points and the abutments due to rocking } \\
\text { motion (column is structurally sound, dam- } \\
\text { age is repairable, the column-base system can } \\
\text { be reused after the applied repair methods, } \\
\text { the whole bridge needs to be reconstructed) }\end{array}$ \\
\hline
\end{tabular}

Table 2: Damage limit states of the rocking bridge bent of Fig. 1(b) [25].

for over a period of time.

Seismic losses are defined as the sum of the seismic consequences weighted with their probability of occurrence. Therefore, the expected seismic losses under a given IM can be expressed as $[39,40]$ :

$$
E(l)=\sum_{i=1}^{n} C_{i} \cdot P_{L S i \mid I M}
$$

where $C_{i}$ represents the seismic consequences, e.g. the repair cost associated with the given damage limit state $i$, and $P_{L S i \mid I M}$ is the conditional probability of the structure to be at the given damage limit state (see Fig. 5). The seismic consequences associated with the given damage limit states are assumed proportional to the reconstruction cost of the bridge [41, 39]:

$$
C_{i}=R C R_{i} \cdot c_{r e c} \cdot W \cdot L
$$

where $W$ and $L$ are the bridge width and length, respectively. $c_{r e c}$ is the reconstruction cost, which for the fixed-base structure of Fig. 1(a) is translated into 2,306 $\$ / \mathrm{m}^{2}$ in present monetary values [42]. $R C R_{i}$ is the repair cost ratio that corresponds to each damage limit state. The repair cost ratios are expressed as a percentage of the reconstruction cost of the bridge, and differ from damage limit state to damage limit state - the more severe the damage, the larger the repair cost ratio. Tables 3, 4 present the pertinent repair cost ratio values for each damage limit state of the examined structures of Fig. 1. 


\begin{tabular}{|c|c|c|c|c|}
\hline \multirow{2}{*}{$\begin{array}{l}\text { Damage } \\
\text { limit } \\
\text { state }\end{array}$} & \multirow{2}{*}{$\begin{array}{l}\text { Repair cost } \\
\text { ratio [37] }\end{array}$} & \multirow[t]{2}{*}{ Repair methods description $[43,44]$} & \multicolumn{2}{|c|}{$\begin{array}{l}\text { Downtime } \\
\text { (days) [37] }\end{array}$} \\
\hline & & & Mean & $\begin{array}{l}\text { Standard } \\
\text { deviation }\end{array}$ \\
\hline LS1 & 0.03 & $\begin{array}{l}\text { Repair slight concrete cracking/spalling at the } \\
\text { column (epoxy injection, patch with concrete, } \\
\text { etc.) }\end{array}$ & 0.6 & 0.6 \\
\hline LS2 & 0.08 & $\begin{array}{l}\text { Repair moderate concrete cracking/spalling at the } \\
\text { column, repair damaged reiforcing bars (patch } \\
\text { with concrete, reinforce and recast, etc.) }\end{array}$ & 2.5 & 2.7 \\
\hline LS3 & 0.25 & $\begin{array}{l}\text { Repair extensive concrete cracking/spalling at the } \\
\text { column, replace/repair longitudinal/transverse re- } \\
\text { inforcing bars (reinforce and recast, potential re- } \\
\text { placement of the column) }\end{array}$ & 75 & 42 \\
\hline LS4 & 1 & $\begin{array}{l}\text { Demolition and reconstruction of the column and } \\
\text { the whole bridge }\end{array}$ & 230 & 110 \\
\hline
\end{tabular}

Table 3: Repair cost ratio and downtime values for each damage limit state of the fixed-base bridge bent of Fig. 1(a).

This study considers nine different seismic hazard scenarios with $T_{R}=40,72,125,225$, $475,975,1,485,2,475$ and 4,975-year return period, which translate into a probability of $71 \%$, $50 \%, 33 \%, 20 \%, 10 \%, 5 \%, 3 \%, 2 \%$ and $1 \%$, respectively, that at least one such event will occur in the next 50 years in the area of focus. The hazard curve of Fig. 3 provides the intensities in terms of $P G V$ values that correspond to the adopted seismic hazard scenarios, i.e. $0.37,0.51$, $0.65,0.83,1.08,1.36,1.53,1.76$ and $2.11 \mathrm{~m} / \mathrm{s}$, respectively. Fig. 6 presents a comparison of the examined structural systems in terms of their expected seismic losses accumulated after the considered seismic hazard scenarios. As a first approach, Fig. 6 shows that for all of the examined seismic hazard scenarios, the rocking bridge bent of Fig. 1(b) provides a significant post-earthquake financial benefit compared to its fixed-base counterpart. In particular, even after a severe seismic event (i.e. with $T_{R}=4,975$-year return period), the rocking bridge bent yields seismic losses which correspond to around $50 \%$ of the construction cost of the structure - a considerable post-earthquake financial benefit.

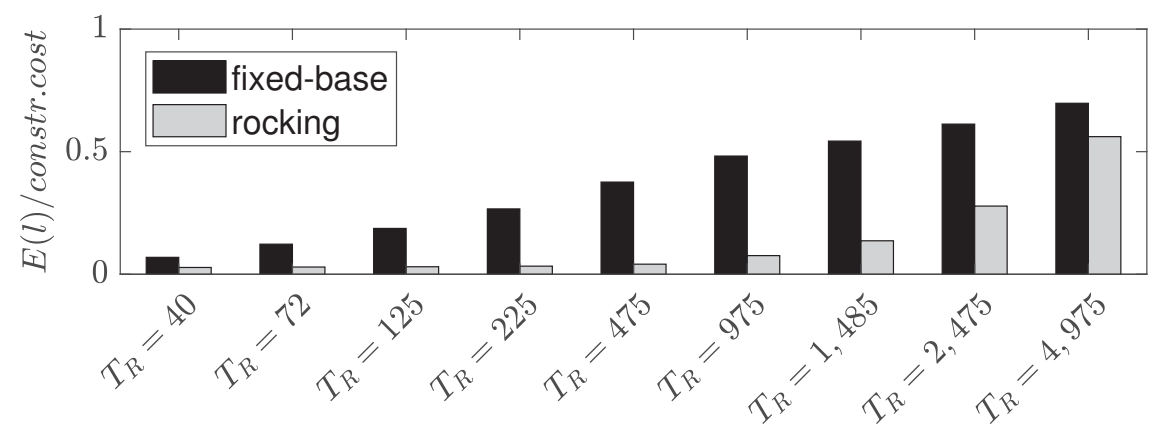

Figure 6: Expected (seismic) losses of the examined bridge bents of Fig. 1 in the aftermath of various seismic hazard scenarios 


\begin{tabular}{|c|c|c|c|c|}
\hline \multirow{2}{*}{$\begin{array}{l}\text { Damage } \\
\text { limit } \\
\text { state }\end{array}$} & \multirow{2}{*}{$\begin{array}{l}\text { Repair cost } \\
\text { ratio [37] }\end{array}$} & \multirow{2}{*}{ Repair methods description } & \multicolumn{2}{|c|}{$\begin{array}{l}\text { Downtime (days) } \\
{[37,45]}\end{array}$} \\
\hline & & & Mean & $\begin{array}{l}\text { Standard } \\
\text { deviation }\end{array}$ \\
\hline LS1 & 0.03 & $\begin{array}{l}\text { Repair slight concrete cracking/spalling at the } \\
\text { column (epoxy injection, patch with concrete, } \\
\text { etc.) }\end{array}$ & 0.6 & 0.6 \\
\hline LS2 & 0.08 & $\begin{array}{l}\text { Repair moderate concrete cracking/spalling at the } \\
\text { column, repair damaged reiforcing bars (patch } \\
\text { with concrete, reinforce and recast, etc.). Repair } \\
\text { damage at the pivot points and the abutments }\end{array}$ & 2.5 & 2.7 \\
\hline LS3 & 1 & $\begin{array}{l}\text { Repair moderate concrete cracking/spalling at the } \\
\text { column, repair damaged reiforcing bars (patch } \\
\text { with concrete, reinforce and recast, etc.). Re- } \\
\text { pair damage at the pivot points and the abut- } \\
\text { ments. Reuse the column-base system after the } \\
\text { applied repair methods. Reconstruction of the } \\
\text { whole bridge }\end{array}$ & 46 & 22 \\
\hline
\end{tabular}

Table 4: Repair cost ratio and downtime values for each damage limit state of the rocking bridge bent of Fig. 1 [25].

\subsection{Resilience Quantification}

Resilience, as a performance indicator, quantifies the recovery (or restoration) functions of a structural system following a seismic event. These recovery functions depend on the associated damage limit states. For instance, a bridge completely damaged needs more time to restore its functionality compared to a slightly damaged bridge. The resilience of the structural systems of Fig. 1 can be quantified under the investigated time-interval (e.g. $\Delta t=365$ days) as [46]:

$$
R=\frac{1}{\Delta t} \int_{t_{0}}^{t_{0}+\Delta t} Q(t) d t
$$

where $t_{0}$ indicates the time-instant the seismic event occurs, and $Q(t)$ is time-variant functionality which herein is expressed as [47]:

$$
Q(t)=\sum_{i=1}^{n} F R_{i}(t) \cdot P_{L S i \mid I M}
$$

where $P_{L S i \mid I M}$ is the conditional probability of the structure to be at the given damage limit state, and $F R_{i}(t)$ denotes the functionality restoration process of the structure for each damage limit state. This study models the functionality restoration process of the examined rocking structure as a normal cumulative distribution function corresponding to each damage limit state $i$ [37]:

$$
F R_{i}(t)=\frac{1}{2}\left[1+\operatorname{erf}\left(\frac{t-\mu_{d_{i}}}{\sqrt{2} \sigma_{d_{i}}}\right)\right]
$$

where $\mu_{d_{i}}$ and $\sigma_{d_{i}}$ represent the mean and standard deviation of the time during which the bridge is under restoration (i.e. downtime). Table 3 presents values mean and standard deviation 


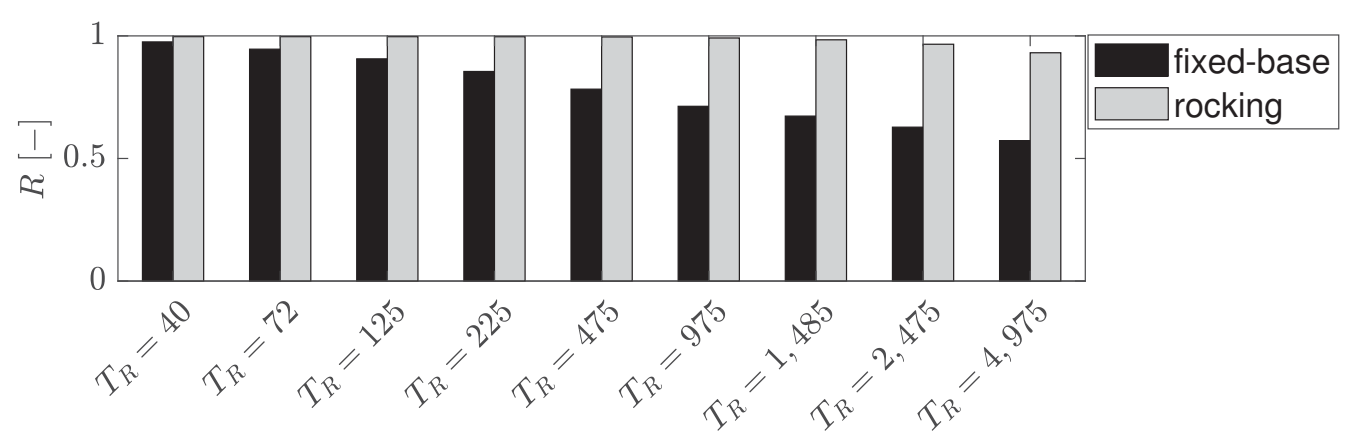

Figure 7: Resilience of the examined bridge bents of Fig. 1 in the aftermath of various seismic hazard scenarios under the investigated time-interval of $\Delta t=365$ days

values of downtime (in days) for the fixed-base bridge bent of Fig. 1(a) proposed by HAZUS [37]. To estimate the corresponding downtime values for a rocking bridge, Mantawy et al. [45] experimentally compared the seismic performance of a rocking versus a conventionally designed (fixed-base) bridge. That study revealed that the construction time of the rocking bridge is, on average, 5 times lower than the construction time of the fixed-base bridge. In other words, when the fixed-base and the rocking bridge bent of Fig. 1 need to be reconstructed (i.e. when LS4 in Table 3 and LS3 in Table 4 are exceeded), the downtime of the rocking structure is considered as $1 / 5$ of the downtime of the fixed-base structure. Table 4 presents the pertinent mean and standard deviation values of downtime for the rocking bridge bent of Fig. 1(b) [25].

Fig. 7 plots the resilience of each structural system and illustrates the dominance of the rocking structure over the conventionally designed (fixed-base) structure after all the examined seismic hazard scenarios. Note that the resilience of the rocking structure starts deteriorating only when a maximum considered earthquake occurs (i.e. with $T_{R}=2,475$-year return period). On the contrary, the resilience of the fixed-base structure is impaired even when a low intensity earthquake occurs (i.e. with $T_{R}=72$-year return period).

In sum, Figs 6, 7 reveal the remarkable financial benefits (i.e. decreased seismic losses and increased seismic resilience) that rocking design offers compared to the conventional fixed-base design, illustrating its potential as a seismic-avoidance design paradigm for bridges.

\section{CONCLUSIONS}

This work evaluates the seismic performance of structural systems, which are particularly attractive for bridge design. It focuses on single-column bridge bents either monolithically connected with the ground (i.e. fixed-base) or able to uplift and exhibit planar rocking motion during an earthquake. It extends the well-established performance-based earthquake engineering framework to compare the examined structural systems in terms of their accumulated seismic losses and resilience in the aftermath of severe seismic hazard scenarios.

The analysis reveals the considerably mitigated (seismic) losses of the examined rocking structure compared to the pertinent losses of the fixed-base structure, illustrating its potential as an economically feasible design solution. Further, results show that even under an extreme seismic hazard event, i.e. with $1 \%$ probability of occurrence in the next 50 years (i.e. $T_{R}=$ 4,975 -year return period), the rocking bridge bent yields financial losses equivalent to $50 \%$ of the construction cost of the bridge - a considerable post-earthquake financial benefit. Further, this paper also unveils the remarkable post-earthquake resilience of the examined rocking structure after various seismic hazard scenarios. Importantly, the rocking bridge bent sustains 
its resilience at the highest level till a maximum considered earthquake occurs (i.e. with $T_{R}=$ 2,475 -year return period and $2 \%$ probability of occurrence in the next 50 years). On the contrary, the resilience of the fixed-base bridge bent is deteriorated even when a low intensity earthquake occurs (i.e. with $T_{R}=72$-year return period and $50 \%$ probability of occurrence in the next 50 years). The above findings redirect our attention to the main post-earthquake benefits of rocking design when used as a seismic isolation technique for bridges and pave the way for a more rational and holistic seismic assessment framework of single-column rocking bridges.

\section{REFERENCES}

[1] G.W. Housner, The behavior of inverted pendulum structures during earthquakes. Bulletin of the Seismological Society of America 53(2), 403-417 (1963).

[2] E.G. Dimitrakopoulos, M.J. DeJong, Revisiting the rocking block: closed-form solutions and similarity laws. Proceedings of the Royal Society A: Mathematical, Physical and Engineering Science 468(2144), 2294-2318 (2012).

[3] M.J. DeJong, E.G. Dimitrakopoulos, Dynamically equivalent rocking structures, Earthquake Engineering \& Structural Dynamics, 43(10), 1543-1563 (2014).

[4] E.G. Dimitrakopoulos, A.I. Giouvanidis, Seismic response analysis of the planar rocking frame. Journal of Engineering Mechanics 141(7), 04015003 (2015).

[5] E.G. Dimitrakopoulos, E.D.W. Fung, Closed-form rocking overturning conditions for a family of pulse ground motions. Proceedings of the Royal Society A: Mathematical, Physical and Engineering Science 472(2196), 20160662 (2016).

[6] M.F. Vassiliou, K.R. Mackie, B. Stojadinovic, A finite element model for seismic response analysis of deformable rocking frames. Earthquake Engineering \& Structural Dynamics 46(3), 447-466 (2017).

[7] M.F. Vassiliou, Seismic response of a wobbling 3D frame. Earthquake Engineering \& Structural Dynamics 47(5), 1212-1228 (2017).

[8] A.I. Giouvanidis, E.G. Dimitrakopoulos, Seismic performance of rocking frames with flag-shaped hysteretic behavior. Journal of Engineering Mechanics 143(5), 04017008 (2017).

[9] J.A. Bachmann, M.F. Vassiliou, B. Stojadinovic, Dynamics of rocking podium structures. Earthquake Engineering \& Structural Dynamics 46(14), 2499-2517 (2017).

[10] J.A. Bachmann, M. Strand, M.F. Vassiliou, M. Broccardo, B. Stojadinovic, Is rocking motion predictable? Earthquake Engineering \& Structural Dynamics 47(2), 535-552 (2018).

[11] A. Dar, D. Konstantinidis, W. El-Dakhakhni, Seismic response of rocking frames with top support eccentricity. Earthquake Engineering \& Structural Dynamics 47(12), 2496-2518 (2018). 
[12] J.A. Bachmann, M.F. Vassiliou, B. Stojadinovic, Rolling and rocking of rigid uplifting structures. Earthquake Engineering \& Structural Dynamics 48(14), 1556-1574 (2019).

[13] N. Reggiani Manzo, M.F. Vassiliou, Displacement-based analysis and design of rocking structures. Earthquake Engineering \& Structural Dynamics 48(14), 1613-1629 (2019).

[14] S. Diamantopoulos, M. Fragiadakis, Seismic response assessment of rocking systems using single degree-of-freedom oscillators. Earthquake Engineering \& Structural Dynamics 48(7), 689-708 (2019).

[15] E. Avgenakis, I.N. Psycharis, An integrated macroelement formulation for the dynamic response of inelastic deformable rocking bodies. Earthquake Engineering \& Structural Dynamics 49(11), 1072-1094 (2020).

[16] K.E. Bantilas, I.E. Kavvadias, L.K. Vasiliadis, Seismic response of elastic multidegree of freedom oscillators placed on the top of rocking storey. Earthquake Engineering \& Structural Dynamics 50(5), 1315-1333 (2021).

[17] G. Vlachakis, A.I. Giouvanidis, A. Mehrotra, P.B. Lourenço, Numerical block-based simulation of rocking structures using a novel universal viscous damping model. Journal of Engineering Mechanics (under review).

[18] A. Palermo, S. Pampanin, Enhanced seismic performance of hybrid bridge systems: Comparison with traditional monolithic solutions. Journal of Earthquake Engineering 12(8), 1267-1295 (2008).

[19] G. Antonellis, M. Panagiotou, Seismic response of bridges with rocking foundations compared to fixed-base bridges at a near-fault site. Journal of Bridge Engineering 19(5), 04014007 (2014).

[20] A. Agalianos, A. Psychari, M.F. Vassiliou, B. Stojadinovic, I. Anastasopoulos, Comparative assessment of two rocking isolation techniques for a motorway overpass bridge. Frontiers in Built Environment 3, 47 (2017).

[21] D. Marriott, S. Pampanin, A. Palermo, Quasi-static and pseudo-dynamic testing of unbonded post-tensioned rocking bridge piers with external replaceable dissipaters. Earthquake Engineering \& Structural Dynamics 38(3), 331-354 (2009).

[22] M. Panagiotou, W. Trono, G. Jen, P. Kumar, C.P. Ostertag, Experimental seismic response of hybrid fiber-reinforced concrete bridge columns with novel longitudinal reinforcement detailing. Journal of Bridge Engineering 20(7), 04014090 (2014).

[23] A.S. Saad, D.H. Sanders, I.G. Buckle, Experimental evaluation of bridge column foundation rocking behavior. Journal of Bridge Engineering 23(11), 04018088 (2018).

[24] Y. Xie, J. Zhang, R. DesRoches, J.E. Padgett, Seismic fragilities of single-column highway bridges with rocking column-footing. Earthquake Engineering \& Structural Dynamics 48(7), 843-864 (2019).

[25] A.I. Giouvanidis, Y. Dong, Seismic loss and resilience assessment of single-column rocking bridges. Bulletin of Earthquake Engineering 18(9), 4481-4513 (2020). 
[26] S. Acikgoz, M.J. DeJong, : The interaction of elasticity and rocking in flexible structures allowed to uplift. Earthquake Engineering \& Structural Dynamics 41(15), 2177-2194 (2012).

[27] M.F. Vassiliou, R. Truniger, B. Stojadinovic, An analytical model of a deformable cantilever structure rocking on a rigid surface: development and verification. Earthquake Engineering \& Structural Dynamics 44(15), 2775-2794 (2015).

[28] A.I. Giouvanidis, E.G. Dimitrakopoulos, Nonsmooth dynamic analysis of sticking impacts in rocking structures. Bulletin of Earthquake Engineering 15(5), 2273-2304 (2017).

[29] J. Zhang, Y. Xie, G. Wu, Seismic responses of bridges with rocking column-foundation: A dimensionless regression analysis. Earthquake Engineering \& Structural Dynamics 48(1), $152-170$ (2019).

[30] P. Fajfar, H. Krawinkler, Seismic design methodologies for the next generation of codes. Taylor \& Francis (1997).

[31] J. Moehle, G.G. Deierlein, A framework methodology for performance-based earthquake engineering. In: Proceedings of the 13th World Conference on Earthquake Engineering, Paper No 679. Vancouver, B.C., Canada (2004).

[32] E.G. Dimitrakopoulos, T.S. Paraskeva, Dimensionless fragility curves for rocking response to near-fault excitations. Earthquake Engineering \& Structural Dynamics 44(12), 2015-2033 (2015).

[33] A.I. Giouvanidis, E.G. Dimitrakopoulos, Rocking amplification and strong-motion duration. Earthquake Engineering \& Structural Dynamics 47(10), 2094-2116 (2018).

[34] J.W. Baker, An introduction to probabilistic seismic hazard analysis. White Paper Version $2.12(1), 79$ (2015).

[35] J.W. Baker, T. Lin, S.K. Shahi, N. Jayaram, New ground motion selection procedures and selected motions for the peer transportation research program. Tech. Rep. PEER Report 2011/3, Pacific Earthquake Engineering Research Center, University of California, Berkeley, CA (2011).

[36] J.S. Jeon, A. Shafieezadeh, D.H. Lee, E. Choi, R. DesRoches, Damage assessment of older highway bridges subjected to three-dimensional ground motions: characterization of shear-axial force interaction on seismic fragilities. Engineering Structures 87, 47-57 (2015).

[37] HAZUS-MH: Multi-hazard loss estimation methodology - earthquake model (technical manual). Tech. Rep. MH MR5, Federal Emergency Management Agency, Washington (2010).

[38] J.W. Baker, Efficient analytical fragility function fitting using dynamic structural analysis. Earthquake Spectra 31(1), 579-599 (2015).

[39] Y. Dong, D.M. Frangopol, D. Saydam, Time-variant sustainability assessment of seismically vulnerable bridges subjected to multiple hazards. Earthquake Engineering \& Structural Dynamics 42(10), 1451-1467 (2013). 
[40] G.A. Anwar, Y. Dong, Y. Li, Performance-based decision-making of buildings under seismic hazard considering long-term loss, sustainability, and resilience. Structure and Infrastructure Engineering 17(4), 454-470 (2020).

[41] J.B. Mander, Fragility curve development for assessing the seismic vulnerability of highway bridges. Tech. rep., University at Buffalo (1999).

[42] Y. Zheng, Y. Dong, Y. Li, Resilience and life-cycle performance of smart bridges with shape memory alloy (SMA)-cable-based bearings. Construction and Building Materials 158, 389-400 (2018).

[43] J. Ghosh, J.E. Padgett, Probabilistic seismic loss assessment of aging bridges using a component-level cost estimation approach. Earthquake Engineering \& Structural Dynamics 40(15), 1743-1761 (2011).

[44] W.K. Lee, S.L. Billington, Performance-based earthquake engineering assessment of a self-centering, post-tensioned concrete bridge system. Earthquake Engineering \& Structural Dynamics 40(8), 887-902 (2011).

[45] I.M. Mantawy, T. Thonstad, D.H. Sanders, J.F. Stanton, M.O. Eberhard, Seismic performance of precast, pretensioned, and cast-in-place bridges: Shake table test comparison. Journal of Bridge Engineering 21(10), 04016071 (2016).

[46] G.P. Cimellaro, A.M. Reinhorn, M. Bruneau, Framework for analytical quantification of disaster resilience. Engineering Structures 32(11), 3639-3649 (2010).

[47] Y. Dong, D.M. Frangopol, Risk and resilience assessment of bridges under mainshock and aftershocks incorporating uncertainties. Engineering Structures 83, 198-208 (2015). 